\title{
Virtual versus jaw simulation in Oral implant education: a randomized controlled trial
}

Baoping Zhang ${ }^{1 \dagger}$, Sihong $\mathrm{Li}^{1 \dagger}$, Shuting Gao ${ }^{1 \dagger}$, Mingfang Hou${ }^{2}$, Hong Chen ${ }^{1}$, Lulu He${ }^{1}$, Yiting $\mathrm{Li}^{1}$, Yumeng Guo , Errui Wang ${ }^{1}$, Rui Cao ${ }^{1}$, Jingyang Cheng ${ }^{1}$, Ruiping $\mathrm{Li}^{1}$ and Kailiang Zhang ${ }^{1,3^{*}}$ (D)

\begin{abstract}
Background: This research aims to investigate the evaluation methods of teaching oral implant clinical courses and estimate the effectiveness of a virtual simulation platform.

Methods: Eighty second- and third-year undergraduates in Lanzhou University were recruited and randomized to either three experimental groups or one control group. The subjects undertook theoretical examinations to test their basic level of knowledge after training in similarly unified knowledge courses. Each student group then participated in an eight-hour operating training session. An operation test on pig mandible was conducted, followed by a second theoretical examination. The assessment consists of three distinct parts: a subjective operating score by a clinical senior teacher, an implant accuracy analysis in cone-beam computed tomography (angular, apical, and entrance deviation), and comparison of the two theoretical examinations. Finally, students completed a questionnaire gauging their understanding of the virtual simulation.
\end{abstract}

Results: There was no significant difference between the four groups in first theoretical examination $(P>0.05)$; the second theoretical scores of the $\mathrm{V}-\mathrm{J}$ and $\mathrm{J}-\mathrm{V}$ group $(62.90 \pm 3.70,60.05 \pm 2.73)$ were significantly higher than the first time $(57.05 \pm 3.92, P<0.05)$, while no difference between the $V(57.10 \pm 3.66)$ and $J(56.89 \pm 2.67)$ groups was found. Thus, the combination of V-J was effective in improving students' theoretical scores. The $\mathrm{V}-\mathrm{J}$ and J-V groups had higher scores on operation $(73.98 \pm 4.58,71.85 \pm 4.67)$ and showed better implant precision.

Conclusion: Virtual simulation education, especially with a jaw simulation model, could improve students' implantology achievements and training. Currently study found that the $\mathrm{V}-\mathrm{J}$ group may performed better than the J-V group in oral implant teaching.

Keywords: Dental education, Theoretical knowledge grade, Implant accuracy examination, Virtual reality model, Preclinical implant training

\footnotetext{
*Correspondence: zhangkllzu@163.com

${ }^{\dagger}$ Baoping Zhang, Sihong Li and Shuting Gao are Co-first Author

${ }^{1}$ School of Stomatology Lanzhou University, Lanzhou 730000, China

${ }^{3}$ Hospital of Stomatology, Lanzhou University, Lanzhou 730000, China

Full list of author information is available at the end of the article
} 


\section{Background}

Digital technologies are rapidly advancing across different and diverse fields. One such promising and widely discussed digital technology is augmented and virtual reality. Augmented reality creates a virtual images and overlays them on a real environment, whereas virtual reality is a digital recreation of reality [1] — both these techniques require the "creation of reality" through computer graphics. In the medical industry, these computerized navigation devices enable its users to aggregate and visualize various medical data. For example, users can employ the helmet display to view medical data and images for surgery [2]. Similarly, doctors are applying virtual reality to treat mental health disorders $[3,4]$, eating disorders [5], and congenital heart disease [6] as well as for drug discovery [7]. Virtual reality has become especially popular in the dental sciences, such as in clinical trials for maxillofacial surgery protocols, human anatomy studies [8], treatment of patients with dental phobia [9], dental anesthesia training [10], and evaluation of endodontic surgery [11].

It is important to acknowledge that digital treatment and training, particularly virtual reality, are set to become mainstays in dentistry as well in the broader clinical and medical industry [1]. This trend is expected to greatly challenge conventional dental clinical practice and learning methods. As oral implant restoration technology advances, one crucial question deals with how to improve the teaching quality of oral implant education in order to train more professional implant clinicians. Previous studies in Europe and Australia showed that, with the integration of implant dentistry in daily dental practice $[12,13]$, more universities were including oral implant-related education in their undergraduate courses. Another study in India shows that $91.7 \%$ of students are eager to learn more about oral implants in college courses [14]. Thus, implant dentistry is slowly become a necessary part of pre-clinical teaching in dental education.

Currently, there is immense regional or geographical heterogeneity in implant education [15]; in different countries, the characteristics of the "basic," "intermediate," "advanced," and "specialist" stages differ [16]. In China's dental implant education system, the simulation laboratory model is considered common, but important, tools for oral experimental teaching and pre-clinical skills training, these tools require specialized equipment and are costly [17]. However, the current model is simple; it cannot simulate difficult cases in actual clinical practice. Thus, only the more experienced trainers are likely to perform complex clinical procedures [18]. In this regard, digital treatment and training that employs virtual reality offer a novel direction in training for dental implant surgery.
The major benefit of applying reality technologies to dental education is in pre-clinical skills training. Students can acquire the necessary skills through repeated digital practice. Virtual reality simulation also gives standardized feedback, which is critical for targeted guidance to students [19]. However, only few applications of virtual simulation technology exist in oral implant surgery training. Thus, the full effect of virtual simulation on such training is inconclusive. Only further research can reveal the best approach and time to incorporate virtual simulation in training programs.

By evaluating the theory and operation procedures of dental students/doctors of implantology, the current study compares the effects of pre-clinical training using a jawbone model, a virtual simulation system, and different orders of a virtual simulation system combined with the jawbone model. This way, current study could find the best approaches to introducing reality technology in implantology training, improve teaching programs, and gauge the effect of such an education in clinical practice.

\section{Methods \\ Participants}

For this study, we selected $80 \mathrm{~s}$ - and third-year undergraduate students of stomatology at Lanzhou University. The random setting as follow: total of 166 students were divided into two groups (male/female) firstly according to gender. Then 40 students were randomly selected in each of two packets using a random-number table consisted of 80 participants ultimately, which can draw random sampling scientifically. The subjects were randomly divided into four groups $(n=20)$ with a similar male-to-female ratio following CONSORT guidelines. The four groups included one control group and three experimental groups: (1) jaw simulation model as control, (2) virtual simulation, (3) virtual-jaw (V-J), (4) jaw-virtual $(\mathrm{J}-\mathrm{V})$. The age distribution of the participants was in the range of 18 to 21 years with no regional differences. None of the subjects had received oral implantology courses before this study. Informed consent was obtained from all participants and the study protocol was approved by the Ethics Committee, School of Stomatology, Lanzhou University.

\section{Study procedure \\ Theory teaching of implantology}

Before receiving the operation training, all students participated in the theory courses and underwent initial assessment (See Fig. 1 for the flow chart). Each lecture was $2 \mathrm{~h}$ long and taught by instructors with more than 10 years of clinical experience. The theoretical content covered implant apparatus, preoperative preparation, basic principles of implant, applied anatomy, and operative procedure, and based on Oral Implantology, second 


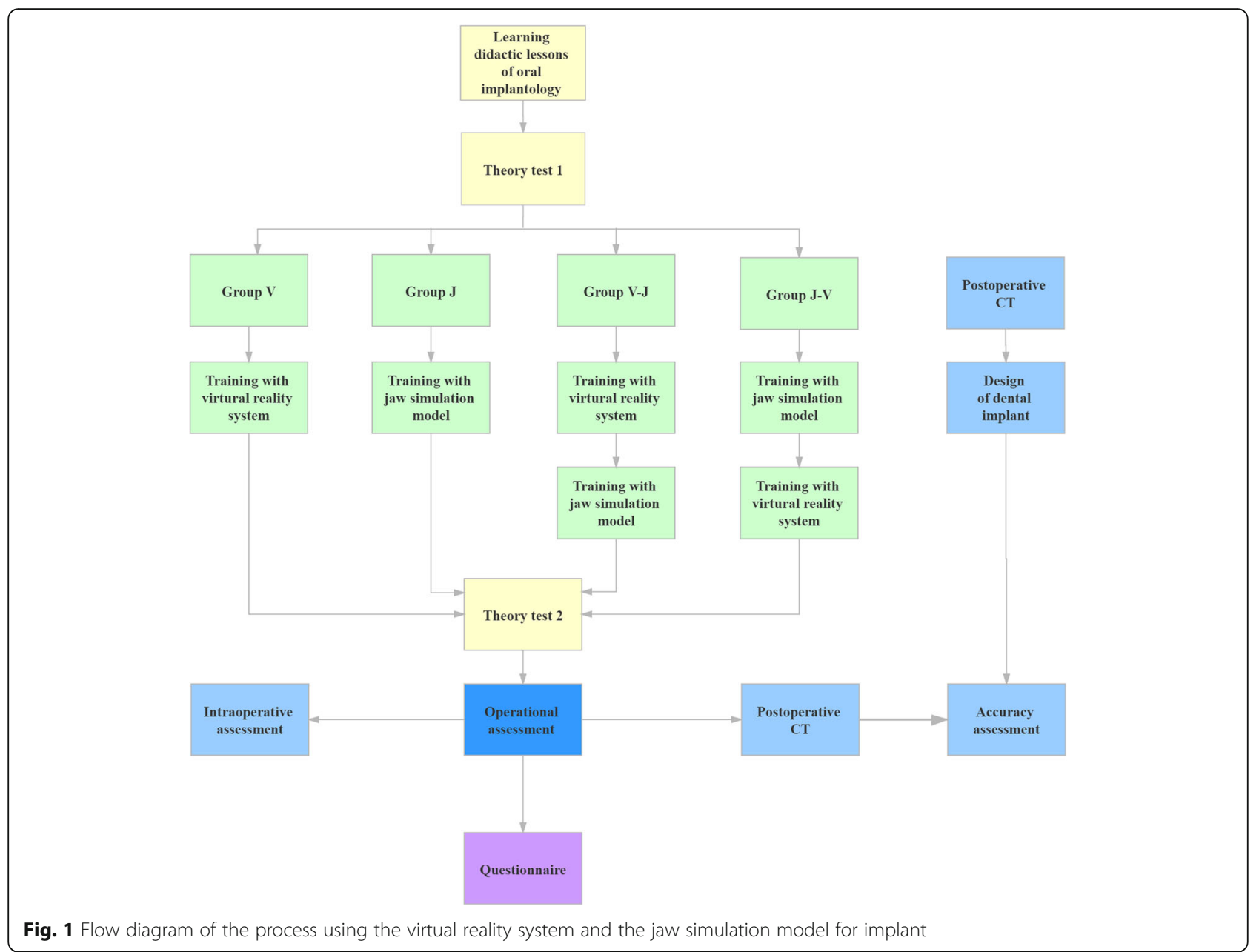

edition [20]. The first theory exam was a multiple-choice questionnaire taken by all participants.

\section{Implanting operation teaching}

The operation training lasted $8 \mathrm{~h}$ over 4 days. The site of operation was the mandibular molars recreated on a virtual simulation system (Zhonghui Technology Institute, UniDental-MS01, China) and jaw simulation model (Fig. 2a, b). The implant systems followed the Dentin implant surgical operation manual [21] and each group used a dental implant toolbox (Fig. 2c). The order of the $\mathrm{V}-\mathrm{J}$ and J-V groups was the opposite, that is, the eighthour long operation was split into two four-hour operations for each group. This way, we evaluated the operational training sequence on effect of teaching.

\section{Preparation before examination}

The mandible of a pig (Yorkshire) was scanned using cone-beam computed tomography (CBCT). The imagine data were imported into a software (Sirona Dental, GALI LEOS Viewer, German). According to the bone condition and anatomical structure, the best implantation site on the mandibular second molar was designed by the teachers (Fig. 3a). Subsequently, the ideal site was assessed for deviation from the actual site (Fig. 3b).

\section{Operational assessment and secondary examination}

In the participants' assessment, the second mandibular molars of a pig were extracted as the implant site. The assessment was double-blinded and evaluated by professional dentists, it included two parts: (1) a subjective evaluation with students' "preoperative preparation" and "intraoperative operation" procedures (See Table 1 for details on the evaluation); (2) an objective evaluation of the images obtained using the CBCT. The former part focused on the standardization and professionalism of the operations, while the latter part was used to judge the effects of implanting. Then, a second theoretical test was conducted to analyze the differences between the first and second testing scores and, thus, determine whether operation training could improve students' theoretical knowledge. 


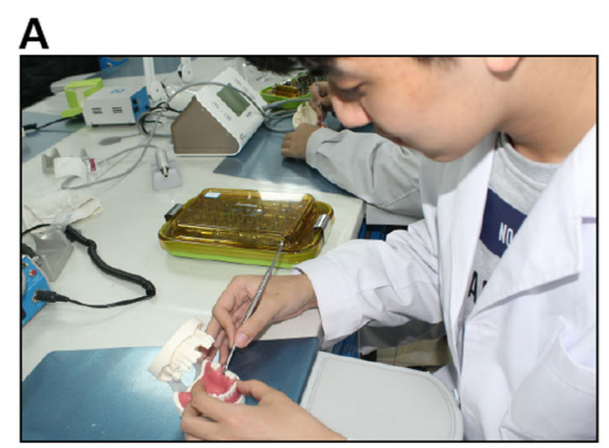

\section{B}

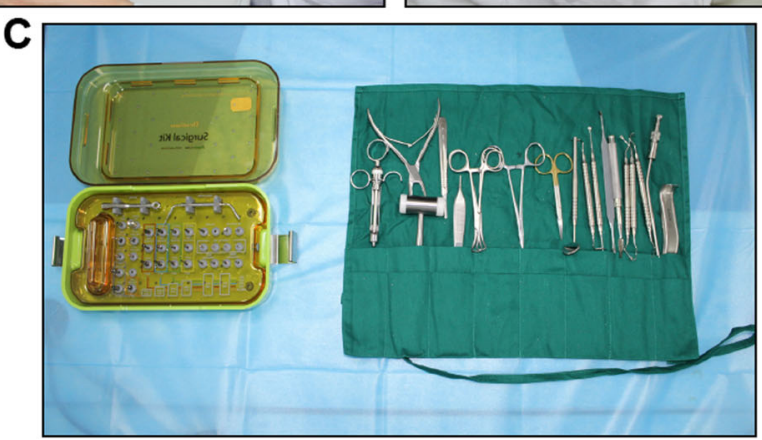

Fig. 2 Training process of implant operation (a) Training with jaw simulation model (b) Training with virtual reality system (c) Implant tool box

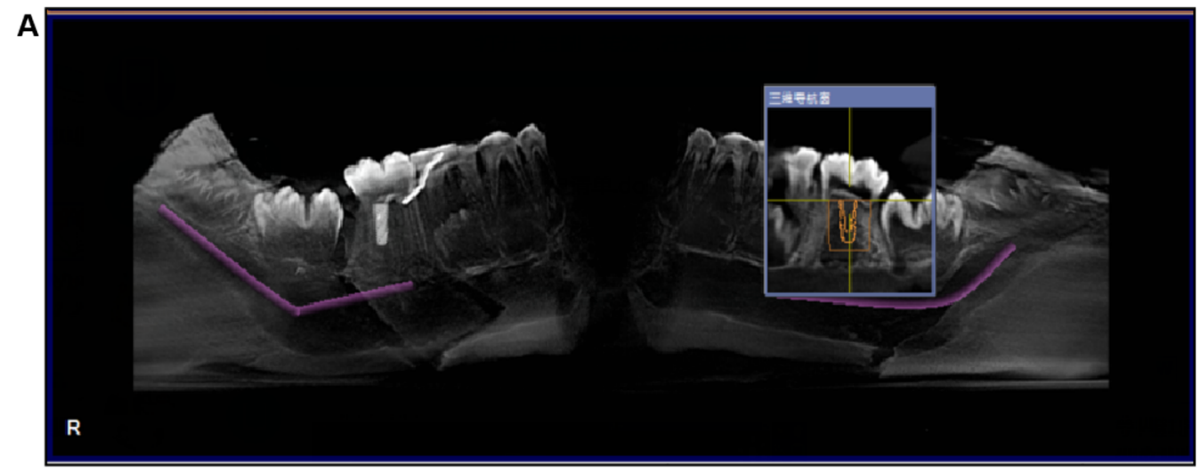

B

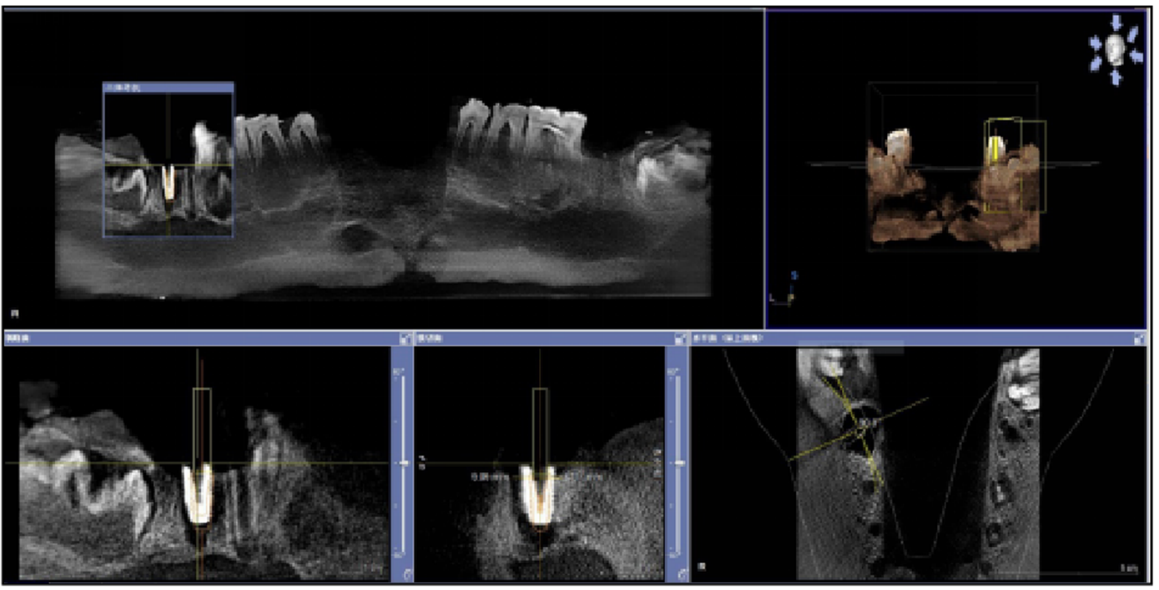

Fig. 3 Analysis with GALILEOS Viewer software (a) Planned implant design (b) Deviation of the placed implant 
Table 1 Planting operation score sheet

\begin{tabular}{|c|c|}
\hline Scoring items & Score \\
\hline \multicolumn{2}{|l|}{ Preoperative preparation } \\
\hline $\begin{array}{l}\text { Dress neatly, asepsis, necessary preoperative } \\
\text { instructions }\end{array}$ & 5 \\
\hline $\begin{array}{l}\text { Assessing implant conditions and designing } \\
\text { surgical procedures }\end{array}$ & 5 \\
\hline $\begin{array}{l}\text { Choosing surgical instruments according to } \\
\text { the surgical plan }\end{array}$ & 5 \\
\hline \multicolumn{2}{|l|}{ Intraoperative operation } \\
\hline \multicolumn{2}{|l|}{ Incision } \\
\hline - Suitable length & 3 \\
\hline - Avoiding damage to adjacent tissues & 3 \\
\hline - Minimally invasive principle & 3 \\
\hline \multicolumn{2}{|l|}{ Dressing the alveolar ridge } \\
\hline - Ensuring the height of the alveolar ridge & 3 \\
\hline - Ensuring the width of the alveolar ridge & 3 \\
\hline \multicolumn{2}{|l|}{ Handling planting nest } \\
\hline - Locating the plantation nest & 5 \\
\hline - Determining planting nest orientation & 5 \\
\hline - Enlarging the diameter of the planting nest & 5 \\
\hline - Formation of planting nests & 5 \\
\hline - Flushing & 5 \\
\hline \multicolumn{2}{|l|}{ Implanting the implant } \\
\hline - Placing the implant & 5 \\
\hline - Removing the carrier & 5 \\
\hline - Closing the implant & 5 \\
\hline - Closing the wound & 5 \\
\hline \multicolumn{2}{|l|}{ Overall effect } \\
\hline Implant position & 5 \\
\hline Implant depth & 5 \\
\hline Implant orientation & 5 \\
\hline Distance between implant and adjacent teeth & 5 \\
\hline Total & 100 \\
\hline
\end{tabular}

\section{Implant accuracy}

The CBCT scan of the implanted site and the imported data were used to evaluate the rationality of implanting in order to calculate the angular, apical, and shoulder deviations. (Fig. 4).

\section{Questionnaire survey}

The degree of satisfaction from the students was gathered through the questionnaire using a Likert scale after the teaching session [22]. Each item was rated, with 5 indicating "strongly agree," 4 indicating "agree," 3 indicating "neither agree nor disagree," 2 indicating "disagree," and 1 indicating "strongly disagree."

\section{Statistics analysis}

A comparison between the four groups was done through an analysis of variance (ANOVA) in case the data conformed to normal distribution with homogeneous variance. For data not conforming to the normal distribution, a non-parameter test was adopted. The study compared the theoretical scores before and after the operation through a paired sample $t$-test. The operational assessment was based on a one-way ANOVA.

\section{Results}

\section{Theoretical examination scores}

The students' first test average scores are shown in Fig. 5 A $(P>0.05)$; the results show no statistically significant difference for the V, J, V-J, and J-V groups $(56.50 \pm 3.88$, $55.26 \pm 3.79 ; 57.05 \pm 3.92 ; 55.05 \pm 3.80$, respectively). Thus, the theoretical lectures imbibed students with similar power to implement their professional knowledge.

The average scores for the second exam after completing the full operation training are shown in Fig. $5 \mathrm{~b}(\mathrm{~V}$ group: $57.10 \pm 3.66$; J group: $56.89 \pm 2.67$; V-J group: $62.90 \pm 3.70$; J-V group: $60.05 \pm 2.73)$, the results show statistical significance in the difference $(P<0.001)$. The V$J$ group was found to be significantly superior to other groups, whereas the J-V group performed better than the J and $\mathrm{V}$ groups. Therefore, the investigation can be stated that operating on the virtual simulation system first would be more conducive to mastering knowledge. There was no difference between the $\mathrm{V}$ and $\mathrm{J}$ groups $(P=0.962)$.

The average difference scores for theory learning before and after the training indicate that the first score of the V-J group $(57.05 \pm 3.92)$ is lower than the second $(62.90 \pm 3.70, P<0.001)$; we find similar results for the J$V$ group (55.05 $\pm 3.80 ; 60.05 \pm 2.73 ; \mathrm{P}<0.001)$. However, the difference in the $\mathrm{V}$ and $\mathrm{J}$ groups was not significant (Fig. 5c). These results show that the model-based simulation fits better than the single one under the same training duration.

\section{Operational assessment}

The assessment scores for the individual groups are reported in Table 2; the mean scores for each group are represented in Fig. 5d. The V-J and J-V groups (73.98 \pm $4.58 ; 71.85 \pm 4.67)$ show higher scores than the $V$ and $M$ groups $(67.275 \pm 4.24 ; 66.15 \pm 3.40)$, with a statistically significant difference. No difference was found between the $\mathrm{V}-\mathrm{J}$ and the $\mathrm{J}-\mathrm{V}$ groups $(P=0.128)$. Similar trends were observed between groups $\mathrm{V}$ and $\mathrm{J}(P=0.417)$.

Table 3 and Fig. 6 describethe experimental results of implant accuracy from the CBCT. The main overall effect in the V-J and J-V groups shows improvement and higher accuracy. That is, the combination of the two training methods helped students improve their implant 


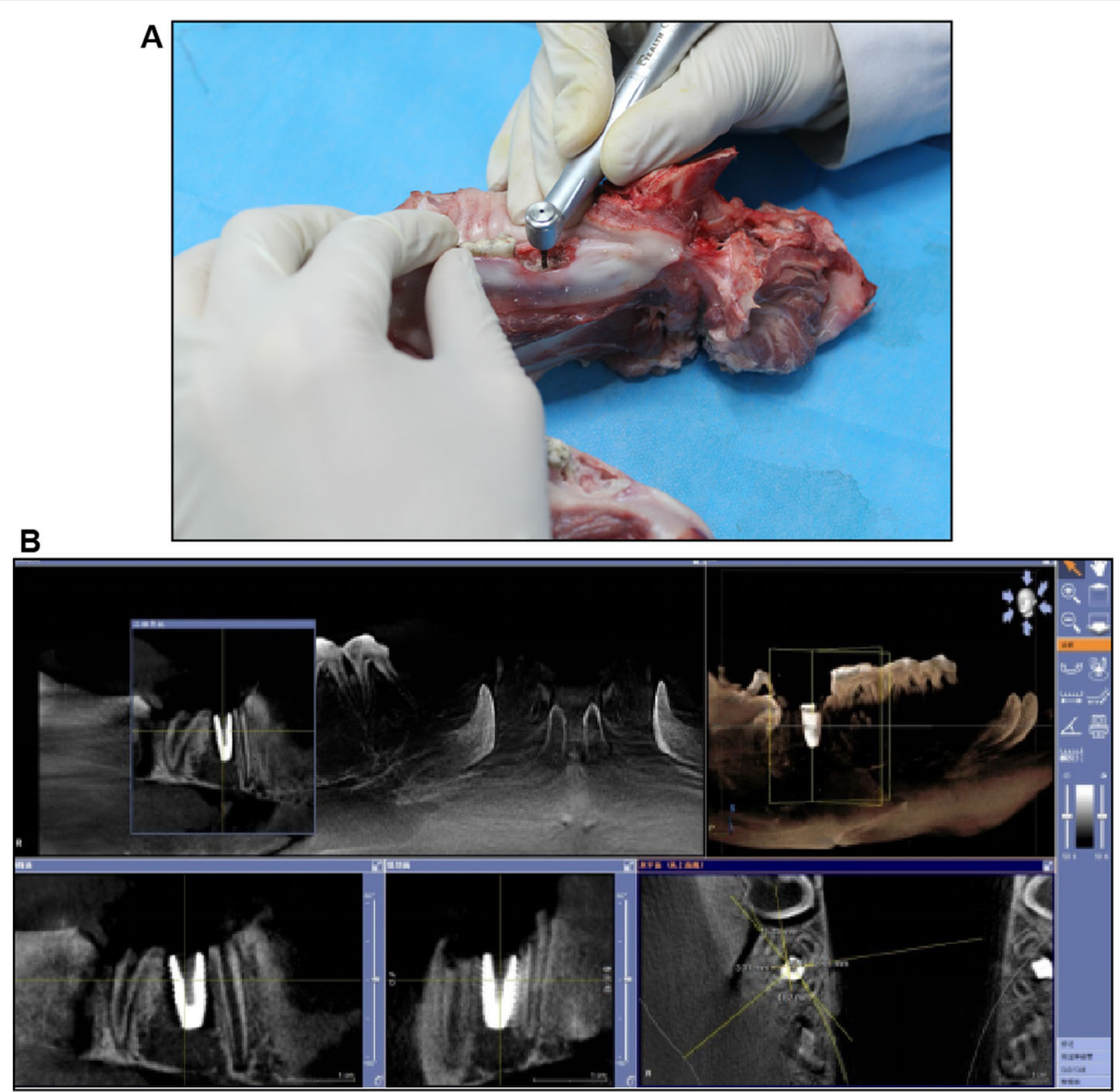

Fig. 4 Implant operated evaluation (a) Subjective evaluation of the process (b) Objective analysis of implant accuracy

clinical skills, but the order (whether $\mathrm{V}-\mathrm{J}$ or $\mathrm{J}-\mathrm{V}$ ) is independent.

\section{Questionnaire}

Table 4 displays the student evaluations of the teaching methods; the evaluation score for the $\mathrm{V}$ and $\mathrm{J}$ groups is 3 , that is, "general." In the joint teaching unit, the score indicates 4 points, that is, "satisfied." Data from the subjective feeling questionnaires show that the V-J and $\mathrm{J}-\mathrm{V}$ groups had better teaching experience.

\section{Discussion}

To achieve optimal methods of teaching oral implant clinical courses and productively applied virtual simulation platform. This study was seek to find a better teaching mode and avoid the disadvantages of traditional teaching. Thus, students can acquire the necessary and adequate skills before beginning their clinic practice.

The results of this study show that, compared with the effects of traditional training, a single virtual simulation system, or a single jaw simulation model, a combination of virtual reality simulation and jaw simulation model is better in terms of theory, operation as well as implant accuracy (shoulder deviation, root deviation, and angle deviation). Jasinevicius [23] had showed that students in contemporary noncomputer-assisted simulation system groups took five times more time than students in virtual reality computer-assisted simulation system groups in the preparation of cavity and full gold crown. De Boer [24] also revealed that dental students could improve their operation dexterity skills by using the Simodont dental trainer to repeatedly practice different levels of force feedback training. Evidently, virtual and augmented reality technologies can promote enjoyment in learning and the acquisition of operational skills. Especially, virtual simulation systems exhibit great potential in dentistry teaching [25], which is consistent with our conclusion. However, the advantages of a pure virtual simulation system are not as obvious as in the prior research. This may be attributed to the different disciplines and equipment required in the virtual simulation system.

In our results, the V-J group made significant progress. Its students achieved higher theoretical scores by first using a virtual simulation system to familiarize themselves 


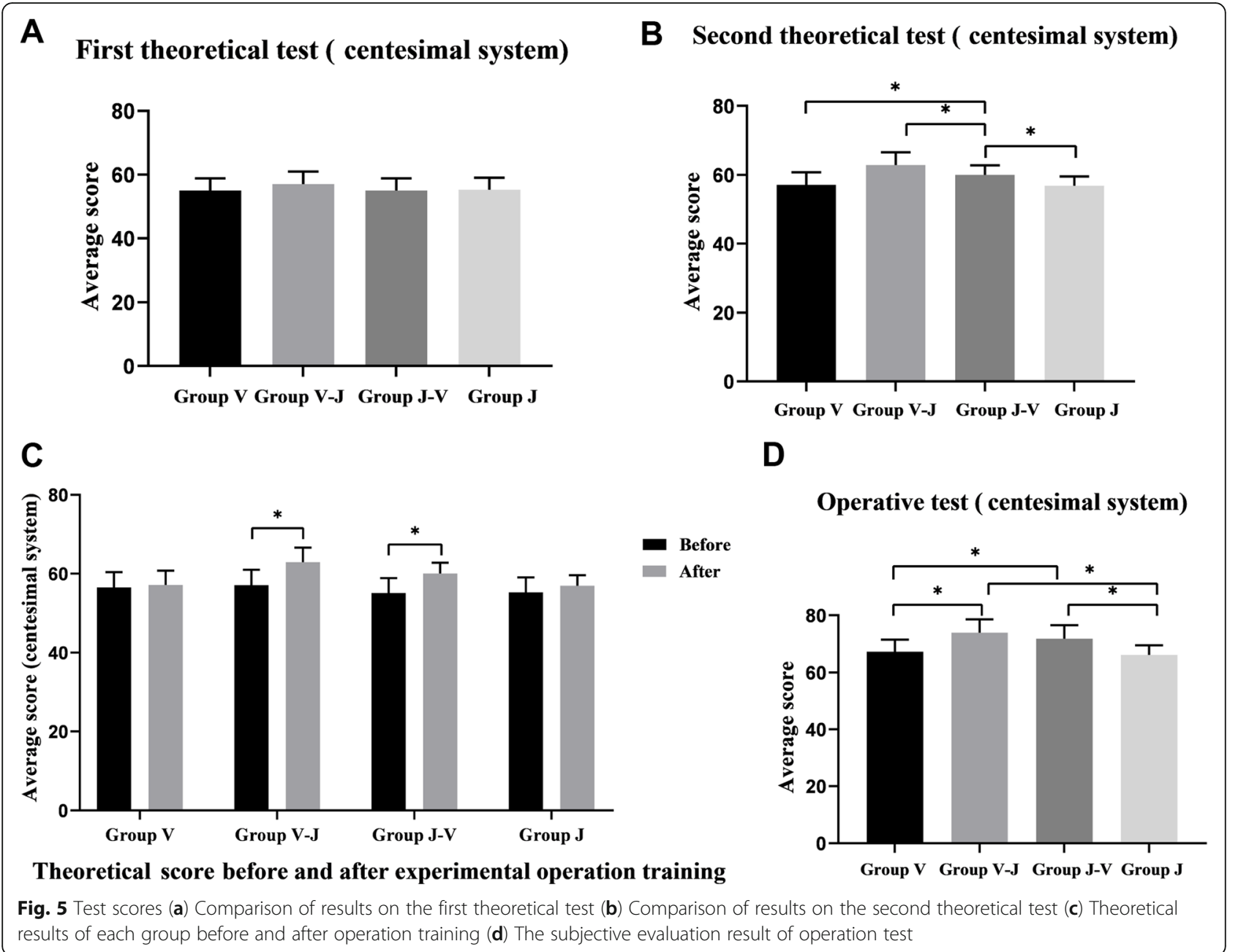

with the dental implant operation process and its main points. Then, they performed physical operations on the jaw model. Teachers believe such a combined education system is better because the virtual simulation technology can simulate the entire dental procedure as well as the corresponding environment-from the patient's clinical admission to the end of the diagnosis and treatment [26]. Thus, students can quickly grasp the entire clinical implantation process. There is also immense theoretical knowledge instilled in the training process. Other virtual
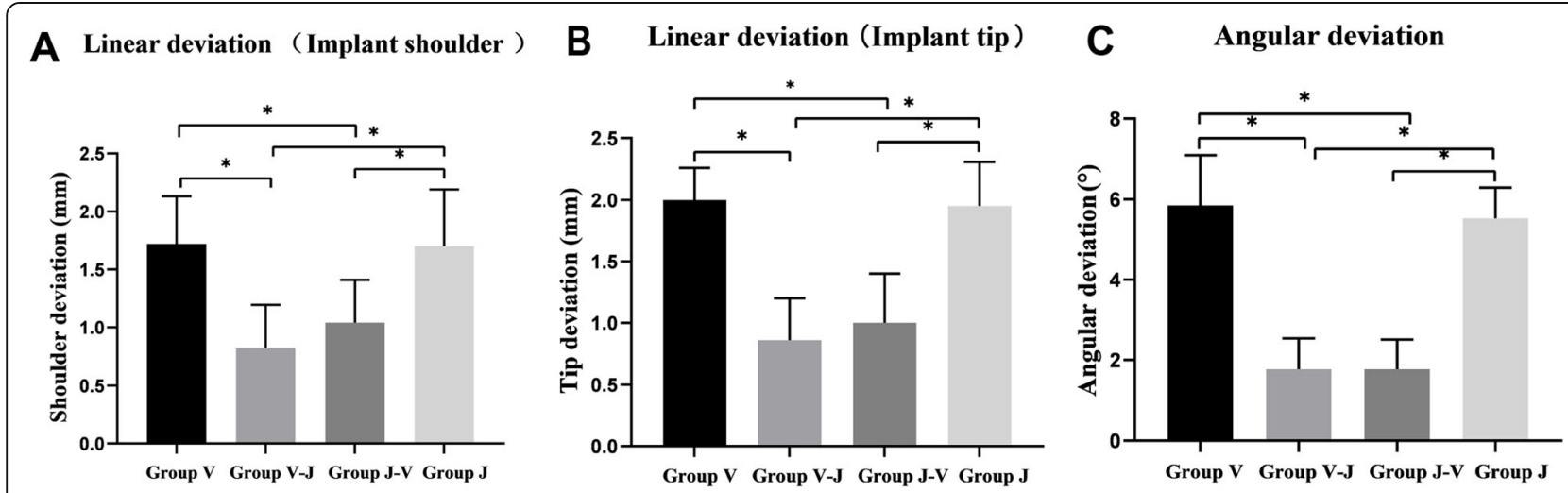

Fig. 6 Comparison of the mean deviations of implants (a) Mean linear deviation of implant shoulder (b) Mean linear deviation of implant tip (c) Mean angular deviation of implant 
Table 2 Operational assessment results

\begin{tabular}{lllll}
\hline Scoring items & Score (Mean \pm SD) & & \\
\cline { 2 - 5 } & V & J & J-V & J-M \\
\hline Preoperative preparation & $10.65 \pm 1.91$ & $9.85 \pm 0.94$ & $11.60 \pm 2.01$ & $12.45 \pm 1.65$ \\
Intraoperative operation & $43.63 \pm 3.50$ & $43.05 \pm 3.24$ & $45.25 \pm 3.51$ & $45.63 \pm 3.05$ \\
Overall effect & $13.00 \pm 1.58$ & $13.25 \pm 1.41$ & $15.00 \pm 1.45$ & $15.90 \pm 1.51$ \\
Total & $67.28 \pm 4.24$ & $66.15 \pm 3.40$ & $71.85 \pm 4.67$ & $73.98 \pm 4.58$ \\
\hline
\end{tabular}

simulation systems can also give targeted feedback during training [27-29], such sustained feedback will maximize the final effect of virtual training [30].

In addition, we should consider students' limited concentration [31], the theoretical knowledge of virtual reality systems should be taught first. Studies have also shown that gender differences can lead to differences in medical tests [32], and hence we grouped our participants to circumvent this difference. In the final evaluation of the implanting operation in this study, compared with other groups, the $\mathrm{V}-\mathrm{J}$ and $\mathrm{J}-\mathrm{V}$ groups showed higher average operation scores, the CBCT planting accuracy was also higher. These results show that our combined training method is conducive to mastering operation skills. However, the sequence of training does not affect the acquisition of implant operations. Although the virtual simulation system can perform screen construction and sensory stimulation in the operation process, the fidelity of its simulation of vision, hearing, and touch cannot be completely compared with actual reality. However, the jaw simulation model can compensate for shortcomings, making a combination system useful.

This research has three important practical significances for future oral implant teaching. First, instructors can use this study as a reference to modify new teaching methods by including virtual simulation systems and jaw simulation models into their teaching courses. This would improve the proficiency in implant skills of dental students. Seifert et al. similarly regarded virtual patient cases as an effective alternative to lecturer-led small group teaching [33]. Second, the use of the virtual simulation system can decrease faculty time in instruction and supervision. Our combined method can save time and human resources expended in implant teaching by reducing trainers' workload. However, the guiding role of teachers cannot be completely replaced by technology. For instance, Lechermeier and Fassnacht [34] found that feedback from professionals of higher status and expertise was still the most effective in training. However, the cost of virtual simulation systems is lower when used for a long time [35]. Third, the result obtained in this survey show students reported greater levels of satisfaction for the combination teaching methods than the students assigned to the traditional teaching method condition. We speculate that they develop an appreciation of this teaching method and the value of acquiring clinical training skills.

Nevertheless, there are some limitations to this study, such as the training time was too short to fully predict the long-term effect of various teaching methods. Because the models of virtual simulation system equipment are not uniform across geographies, simulators use different training levels, they have different contexts and levels of difficulty [36]. Due to this limitation, the results of our experiment cannot explain the application value of all virtual simulation systems. Although the pig has proven to be a suitable bio-model for both research purposes and for training medical professionals because of its similarity to humans [37], the effect of using it for the evaluation of dental implant operations is still not completely equivalent to real clinical cases. Future studies should examine the long-term application effect of the virtual simulation system, especially its optimal application period in the teaching process, as these questions remain unclear, but significant. In addition, it is of great importance to develop more realistic virtual simulation equipment.

Table 3 Deviation of implant accuracy

\begin{tabular}{|c|c|c|c|c|c|}
\hline \multirow[t]{2}{*}{ Deviations } & \multicolumn{4}{|c|}{ Groups (Mean \pm SD) } & \multirow[t]{2}{*}{$P$ value } \\
\hline & V & J & $V-J$ & $J-V$ & \\
\hline \multicolumn{6}{|l|}{ Linear deviation (mm) } \\
\hline Implant tip & $2.00 \pm 0.26$ & $1.95 \pm 0.36$ & $0.86 \pm 0.34$ & $1.00 \pm 0.40$ & $<0.001$ \\
\hline Implant shoulder & $1.72 \pm 0.41$ & $1.70 \pm 0.49$ & $0.82 \pm 0.37$ & $1.04 \pm 0.37$ & $<0.001$ \\
\hline Angular deviation $\left({ }^{\circ}\right)$ & $5.85 \pm 1.25$ & $5.53 \pm 0.76$ & $1.77 \pm 0.77$ & $1.77 \pm 0.74$ & $<0.001$ \\
\hline
\end{tabular}


Table 4 Questionnaire survey

\begin{tabular}{|c|c|c|c|c|}
\hline \multirow[t]{2}{*}{ Project Evaluation Score } & \multicolumn{4}{|c|}{ Groups (Mean \pm SD) } \\
\hline & $\mathrm{V}$ & J & $J-V$ & $J-M$ \\
\hline Course focus & $3.45 \pm 0.50$ & $3.15 \pm 0.36$ & $4.75 \pm 0.43$ & $4.70 \pm 0.46$ \\
\hline Course interest & $3.80 \pm 0.40$ & $3.85 \pm 0.36$ & $4.80 \pm 0.40$ & $4.65 \pm 0.48$ \\
\hline Course richness & $3.60 \pm 0.49$ & $3.40 \pm 0.49$ & $4.85 \pm 0.36$ & $4.80 \pm 0.40$ \\
\hline Acquisition of konwledge & $3.30 \pm 0.46$ & $2.95 \pm 0.22$ & $3.90 \pm 0.44$ & $4.25 \pm 0.43$ \\
\hline Combine theory with practice & $3.70 \pm 0.46$ & $3.35 \pm 0.48$ & $4.85 \pm 0.36$ & $4.60 \pm 0.49$ \\
\hline Improvement of clinical skills & $3.80 \pm 0.40$ & $3.25 \pm 0.43$ & $4.70 \pm 0.46$ & $4.85 \pm 0.36$ \\
\hline The activity of the class atmosphere & $3.35 \pm 0.48$ & $3.90 \pm 0.30$ & $4.85 \pm 0.36$ & $4.60 \pm 0.49$ \\
\hline Improvement of learning motivation & $3.35 \pm 0.48$ & $3.20 \pm 0.40$ & $4.70 \pm 0.46$ & $4.85 \pm 0.36$ \\
\hline Satisfaction with the use of laboratory & $3.60 \pm 0.49$ & $3.50 \pm 0.50$ & $4.85 \pm 0.48$ & $4.85 \pm 0.36$ \\
\hline Interaction between teachers and students & $3.55 \pm 0.50$ & $3.05 \pm 0.22$ & $4.90 \pm 0.30$ & $4.55 \pm 0.50$ \\
\hline
\end{tabular}

\section{Conclusion}

The present preliminary study could provide an interaction training method for implantology, combines the virtual simulation system and the jaw simulation model has a positive effect on theoretical knowledge and preclinical skills.

\section{Acknowledgements}

We would like to thank for all the student's wonderful cooperation and Ruiming Zhang offer CBCT's technical support.

\section{Authors' contributions}

BPZ and MFH conceived the design. KLZ supervised the study. SHL, HC, STG and LLH performed all the clinical biology experiments. YTL, JYC and RC analyzed the data. ERW and YMG wrote the manuscript. BPZ and $\mathrm{KLZ}$ reviewed the manuscript. All authors reviewed and approved the manuscript.

\section{Funding}

This work was supported by Lanzhou University's "Double First Class" Guided Project-Outstanding Innovative Talent Training Program (316000-561119101). The funder had role in the design and conduct of the study and decision to submit the manuscript for publication.

\section{Availability of data and materials}

The datasets used and/or analyzed during the current study are available from the corresponding author on reasonable request.

\section{Ethics approval and consent to participate}

This study was approved by Ethics Committee of the School of Stomatology Lanzhou University (No. LZUKQ-2019-25), and all students provided written informed consent to participate in this study.

\section{Consent for publication}

Not applicable.

\section{Competing interests}

The authors declare that they have no competing interests.

\section{Author details}

${ }^{1}$ School of Stomatology Lanzhou University, Lanzhou 730000, China. ${ }^{2}$ College of Medicine, Lanzhou University, Lanzhou 730000, China. ${ }^{3}$ Hospital of Stomatology, Lanzhou University, Lanzhou 730000, China.
Received: 24 February 2020 Accepted: 15 July 2020

Published online: 18 August 2020

\section{References}

1. Huang TK, Yang CH, Hsieh YH, Wang JC, Hung CC. Augmented reality (AR) and virtual reality (VR) applied in dentistry. Kaohsiung J Med Sci. 2018:34(4):243-8

2. Casap N, Wexler A, Tarazi E. Application of a surgical navigation system for implant surgery in a deficient alveolar ridge postexcision of an odontogenic myxoma. J Oral Maxillofac Surg. 2005;63(7):982-8.

3. Freeman $\mathrm{D}$, Reeve $\mathrm{S}$, Robinson $\mathrm{A}$, et al. Virtual reality in the assessment, understanding, and treatment of mental health disorders. Psychol Med. 2017:47(14):2393-400.

4. Maples-Keller JL, Yasinski C, Manjin N, Rothbaum BO. Virtual realityenhanced extinction of phobias and post-traumatic stress. Neurotherapeutics. 2017;14(3):554-63.

5. Clus D, Larsen ME, Lemey C, Berrouiguet $\mathrm{S}$. The use of virtual reality in patients with eating disorders: systematic review. J Med Internet Res. 2018; 20(4):e157.

6. Ong CS, Krishnan A, Huang CY, et al. Role of virtual reality in congenital heart disease. Congenit Heart Dis. 2018;13(3):357-61.

7. Liu XH, Wang T, Lin JP, Wu MB. Using virtual reality for drug discovery: a promising new outlet for novel leads. Expert Opin Drug Discov. 2018;13(12): 1103-14.

8. Joda T, Gallucci GO, Wismeijer D, Zitzmann NU. Augmented and virtual reality in dental medicine: a systematic review. Comput Biol Med. 2019;108: 93-100.

9. Wiederhold MD, Gao K, Wiederhold BK. Clinical use of virtual reality distraction system to reduce anxiety and pain in dental procedures. Cyberpsychol Behav Soc Netw. 2014;17(6):359-65.

10. Correa CG, Machado M, Ranzini E, Tori R, Nunes FLS. Virtual reality simulator for dental anesthesia training in the inferior alveolar nerve block. J Appl Oral Sci. 2017:25(4):357-66.

11. Yin MS, Haddawy P, Suebnukarn S, Rhienmora P. Automated outcome scoring in a virtual reality simulator for endodontic surgery. Comput Methods Prog Biomed. 2018;153:53-9.

12. Sanz M, Saphira L. Competencies in implant therapy for the dental graduate: appropriate educational methods. Eur J Dent Educ. 2009;13(Suppl 1):37-43.

13. Mattheos N, Ivanovski S, Sambrook P, Klineberg I. implant dentistry in Australian undergraduate dental curricula: knowledge and competencies for the graduating dentist. Aust Dent J. 2010;55(3):333-8.

14. Chaudhary S, Gowda TM, Kumar TA, Mehta DS. Knowledge, attitudes, and perceptions of undergraduate dental students toward dental implants--an all India survey. Implant Dent. 2015;24(2):160-5.

15. Dragan IF, Pirc M, Rizea C, Yao J, Acharya A, Mattheos N. A global perspective on implant education: cluster analysis of the "first dental implant experience" of dentists from 84 nationalities. Eur J Dent Educ. 2019; 23(3):251-65. 
16. Donos N, Mardas N, Buser D. An outline of competencies and the appropriate postgraduate educational pathways in implant dentistry. Eur J Dent Educ. 2009;13(Suppl 1):45-54.

17. Buchanan JA. Use of simulation technology in dental education. J Dent Educ. 2001;65(11):1225-31.

18. Cheung MC, Hopcraft MS, Darby IB. Implant education patterns and clinical practice of general dentists in Australia. Aust Dent J. 2019;64(3):273-81.

19. Liu L, Zhou R, Yuan S, et al. Simulation training for ceramic crown preparation in the dental setting using a virtual educational system. Eur J Dent Educ. 2020;24(2):199-206.

20. Yucheng Su. Implant Dentistry. 2rd ed. Beijing: People's Health Publishing House; 2014.

21. Dentium: The Dentium register. http://www.dentium.com.cn/. Accessed 20 Feb 2020.

22. Bishop PA, Herron RL. Use and misuse of the Likert item responses and other ordinal measures. Int J Exerc Sci. 2015;8(3):297-302.

23. Jasinevicius TR, Landers M, Nelson S, Urbankova A. An evaluation of two dental simulation systems: virtual reality versus contemporary noncomputer-assisted. J Dent Educ. 2004;68(11):1151-62.

24. de Boer IR, Lagerweij MD, Wesselink PR, Vervoorn JM. The effect of variations in force feedback in a virtual reality environment on the performance and satisfaction of dental students. Simul Healthc. 2019;14(3): 169-74.

25. Plessas A. Computerized virtual reality simulation in preclinical dentistry: can a computerized simulator replace the conventional phantom heads and human instruction? Simul Healthc. 2017;12(5):332-8.

26. Cederberg RA, Bentley DA, Halpin R, Valenza JA. Use of virtual patients in dental education: a survey of U.S. and Canadian dental schools. J Dent Educ. 2012;76(10):1358-64.

27. Sapkaroski D, Baird M, Mclnerney J, Dimmock MR. The implementation of a haptic feedback virtual reality simulation clinic with dynamic patient interaction and communication for medical imaging students. J Med Radiat Sci. 2018;65(3):218-25.

28. Wang D, Li T, Zhang Y, Hou J. Survey on multisensory feedback virtual reality dental training systems. Eur J Dent Educ. 2016;20(4):248-60.

29. Hagelsteen K, Langegard A, Lantz A, Ekelund M, Anderberg M, Bergenfelz A. Faster acquisition of laparoscopic skills in virtual reality with haptic feedback and 3D vision. Minim Invasive Ther Allied Technol. 2017;26(5):269-77.

30. Archer JC. State of the science in health professional education: effective feedback. Med Educ. 2010;44(1):101-8.

31. Bradbury NA. Attention span during lectures: 8 seconds, 10 minutes, or more? Adv Physiol Educ. 2016;40(4):509-13.

32. Haq I, Higham J, Morris R, Dacre J. Effect of ethnicity and gender on performance in undergraduate medical examinations. Med Educ. 2005; 39(11):1126-8.

33. Seifert LB, Socolan O, Sader R, Russeler M, Sterz J. Virtual patients versus small-group teaching in the training of oral and maxillofacial surgery: a randomized controlled trial. BMC Med Educ. 2019:19(1):454.

34. Lechermeier J, Fassnacht M. How do performance feedback characteristics influence recipients' reactions? A state-of-the-art review on feedback source, timing, and valence effects. Manag Rev Q. 2018;68(4):145-93.

35. Farra SL, Gneuhs M, Hodgson E, Kawosa B, Miller ET, Simon A, Timm N, Hausfeld J. Comparative cost of virtual reality training and live exercises for training Hospital Workers for Evacuation. Comput Inform Nurs. 2019;37(9): 446-54.

36. Ullrich $\mathrm{S}$, Kuhlen T. Haptic palpation for medical simulation in virtual environments. IEEE Trans Vis Comput Graph. 2012;18(4):617-25.

37. Kyllar M, Stembirek J, Danek Z, Hodan R, Stransky J, Machon V, Foltan R. A porcine model: surgical anatomy of the orbit for maxillofacial surgery. Lab Anim. 2016;50(2):125-36.

\section{Publisher's Note}

Springer Nature remains neutral with regard to jurisdictional claims in published maps and institutional affiliations.

Ready to submit your research? Choose BMC and benefit from:

- fast, convenient online submission

- thorough peer review by experienced researchers in your field

- rapid publication on acceptance

- support for research data, including large and complex data types

- gold Open Access which fosters wider collaboration and increased citations

- maximum visibility for your research: over $100 \mathrm{M}$ website views per year

At BMC, research is always in progress.

Learn more biomedcentral.com/submissions 